\title{
Evaluation of Family Functions of Parents with Cerebral Palsy Children
}

\author{
N. Melis MİSYAĞCI ${ }^{1}$, Lale A. BÜYÜKGÖNENÇ
}

\begin{abstract}
Background: Family functions of families with children with cerebral palsy (CP) may be affected in to care burden directly.

Objectives: In this study, it was aimed to evaluate the family functions of parents of children with cerebral palsy $(\mathrm{CP})$.

Methods: The sample of the descriptive study was made up of the parents of 118 children diagnosed with CP in Istanbul and Ankara provinces. All of the data obtained in the study were evaluated with SPSS 23.0 for Windows statistical package program.

Results: The average scores of the parents who have children with $\mathrm{CP}$ who participated in the study on the Family Assessment Scale dimensions ranged from $1.62 \pm 0.54 / 0.62$ to $2.40 \pm 0.58$. Depending on the sociodemographic characteristics of the parents, the dimensions of the family assessment scale are related to the age, marital status, educational status, age of spouses, education status of spouses, employment status, income status, number of children, having another disabled child, sharing care, child; A significant correlation was found between the child's other health problems and school attendance, degree of cerebral palsy, time elapsed since diagnosis, and use of spasticity-reducing medication $(\mathrm{p}<.05)$.

Conclusion: Nurses and health professionals should consider the child and the family as a whole while providing care, and should evaluate the functions of the family with all its sub-dimensions, considering that the problem in the family may also affect the child's care.
\end{abstract}

Keywords: cerebral palsy, child, family, family function

\section{Introduction}

Cerebral palsy (CP) has been defined as one of the most common motor disorders in childhood, and it is a group of permanent disorders of movement and posture

\footnotetext{
1 Cyprus Science University Faculty of Health Sciences Nursing Department Lecturer DOI: 10.17932/EJOH.2020.022/ejoh_v01i1005
} 
development due to non-progressive damage to the developing fetus or infant's brain during the antenatal, perinatal or early postnatal period $(1,2)$. According to the National Institute of Neurological Disorders and Stroke, it has been defined as a group of neurological disorders that are seen in the neonatal and early childhood periods and permanently cause deficits in muscular coordination, balance, and movement (3). CP causes a series of pathophysiological changes which are related to apoptosis in the neuron and inflammatory amendments in the central nervous system (4). CP happens in 1 in 500 live births. Generally, the diagnosis has been made between age 12 and 24 months. However, it can be made before 6 months' corrected age (5). Important risk factors causing CP; placental anomalies are grouped as major and minor birth defects, low birth weight, meconium aspiration, emergency cesarean section, birth asphyxia, neonatal seizures, respiratory distress syndrome, hypoglycemia, and neonatal infections (6).

Family is known one of the important and basic components of society and is a structure in which parents take the equal responsibility of taking care of their children (7). While the family functions of families with healthy children are dynamic and variable, in addition to the existing responsibilities of families with disabled children, the problems arising from the caregiver roles. These crisis makes family functions more sensitive and an issue that needs to be considered (8). The fact that the child joining the family does not develop normally, and the caregiving process is long and challenging, sometimes causes psychological, socioeconomic, social and family problems $(8,9)$.

Family members with a disabled child experience high rates of anxiety, sorrow, anger, shock, denial, loneliness, social isolation, disappointment and regret. They also have difficulty adapting to multiple problems and conflicts as well as maintaining balance between family members. In addition, their ability to cope is low compared to healthy families $(9,10,11,12)$. Considering all this reasons, it gains importance in analyzing existing or potential problems before it emerges.

Any factor that disrupts family dynamics affects family functions. If the family structure is vulnerable to coping with these changes, various impairments of family function are observed. Some factors that cause internal and external crises disrupt the family structure. For example environmental factors, sociological changes, economic conditions which cause financial problems, illness and health status, presence of disabled children in a family, parents' perception of family structure, negative parent-child relationships, parental behaviours and society's perspective on family are some of the factors that affect family functions (13).

Because family is a structure that forms the basis of a society formed by the combination of two different people to achieve the same goal, some problems affect the family in the short term but some of them require lifelong family 
adaptation. Families with healthy functions are expected to stay healthy or adapt, even if problems arise. The adaptation of the family to these changes depends on the strength in its internal structure and external support. Having a disabled child is an important factor that changes family functions in many ways. Therefore, it is very important to increase their strength, help to deal with disability with family centered nursing care and to reorganize family functions accordingly $(14,15)$. In this study, it is aimed to evaluate the family functions of parents who have a child with CP.

\section{Materials and Methods}

Research Type: This research is a descriptive and cross-sectional study.

Place and Time of the Research: The research was conducted at the Children with Cerebral Palsy Association (SERÇEV) Istanbul branch, special education school in Ankara, Turkey Spastic Children's Foundation (TSÇV) between 08.02.201729.06.2017.

\section{Research Population and Sample}

The research population formed by the parents of children with SP registered to TSÇV, Istanbul branch of SERÇEV and the special education school in Ankara. According to the inclusion criteria; A total of 118 families, 59 of whom were registered in Turkish Spastic Children 6 of whom were registered in Istanbul branch of SERÇEV and 53 of whom were enrolled in a special education school in Ankara were included in the study.

\section{Inclusion Criteria}

Sample selection criteria; Parents have children in the 0-18 age group with a diagnosis of $\mathrm{CP}$, being literate and having no communication barriers.

Data Collection Tools

The data in the study were collected by using face-to-face interview method with Socio-demographic Question Form and Family Assessment Device (FAD).

Sociodemographic Question Form (SQF):

It is a form consisting of 25 questions developed by the researcher to determine the demographic characteristics of the parents and children participating in the study. In this form, the age of the parent (mother or father), marital status, educational status, income level, employment status, the number of children with disabilities, the presence of other children with disabilities, the status of receiving help in the care of the child, the parents' education about $\mathrm{CP}$, There are questions that are thought to affect family function such as the child's age, gender, age at which the diagnosis of $\mathrm{CP}$ was diagnosed, the degree of spasticity, the use of drugs that 
reduce spasticity, the health problems experienced in addition to $\mathrm{CP}$, the status of attending school, and whether or not he received regular rehabilitation services (16).

Family Assessment Device (FAD):

Developed within the framework of the Family Research Program by Brown University School of Medicine, Department of Psychiatry and Human Behaviors and Butler Hospital in the USA, it is a measurement tool that determines the subjects in which the family can or cannot fulfill its functions. It was obtained by applying the McMaster Model of Family Functioning to families clinically and consists of seven subscales. These are the sub-dimensions of the McMaster Model, six of which address each problem area in family functions one by one, and one focuses on general functions. Some of the questions describe healthy functions and some describe unhealthy functions. The validity and reliability study of the scale was conducted by Ebstein et al and also Turkish validity and reliability study of Turkey gained by Bulut (17). The scale consists of 60 items, 32 of which are reverse-coded, and evaluates seven different parts. These sections (subscales); problem solving, communication, roles, emotional responsiveness, showing due care, behavioral control and general functions.

In FAD, points from 1 to 4 can be given to options. Those who chose the option "I totally agree" got 1 point, those who chose the "strongly agree" option got 2 points, those who said "slightly agree" got 3 points, and those who answered "I totally disagree" got 4 points. Since some items were prepared positively and some were prepared in a negative way, the answer "I totally agree" in some expressions and "I totally disagree" in others indicates being healthy. The evaluation of FAD is obtained by dividing the total score obtained from a dimension for each individual by the number of questions in that dimension and obtaining the average score (18).

\section{Collection of Data}

The data in the study were collected using face-to-face interview method with Socio-demographic Question Form and FAD. In this study, the data were collected between February 22 -April 62017 on different days of the week. The data was collected in the range of 09:00 to 17:00 hours according to availability of families in Spastic Children Foundation before or after the appointment time at the family waiting room. The data collection process in the special education center in Ankara was carried out by the researcher in the parents' waiting room of the school for a day, between 13.00-16.00. At SERÇEV, data were collected through the association's Istanbul representative. It took about 15 minutes to fill in the Personal Information Form and FAD. 


\section{Evaluation of Data}

All of the data obtained in the study were processed with SPSS 23.0 for Windows statistical package program. Before proceeding of the data, it was checked whether the data were within the limits determined by data collection tools (SQF and FAD), and whether it contained errors and serious deficiencies. Then, the normality distributions of the data groups were examined with the KolmogorovSmirnov (K-S) test for the selection of statistical analyzes to be applied depending on the purpose and research questions of the study. T-test and Mann Whitney $\mathrm{U}$ tests were used to analyze the data. In this study, p value was accepted as 0.05 .

Research Questions

A total of seven questions and related question subtitles were used in the study. These are listed as follows;

1. Do some sociodemographic characteristics of parents who have a child with $\mathrm{CP}$ affect family functions?

\section{1.a. Age}

1.b. Marital status

1.c. Education status

1.d. Age of spouse

1.e. Education status of spouse

1.f. Employment status

1.g. Income status

1.h Number of children owned

1.i. Disability in other children

1.j. The state of sharing the care of the child

1.k. Training status about CP

2. Do some sociodemographic characteristics of the child affect the family functions of the parents?

2 a. Child's age

2.b. Gender

2.c. Age at which $\mathrm{CP}$ was diagnosed

2.d. Using a drug that reduces spasticity 
3. Does the child's degree of spasticity affect the parents' family functions?

4. Do the presence of other health problems of the child affect the family functions of the parents?

5. Does getting help in the care of the child affect the family functions of the parents?

6. Does the child's attendance at school affect the family functions of the parents?

7. Does regular use of rehabilitation services affect the family functions of the parents?

Ethical Aspect of the Research

Before starting the research, the study was submitted to the Koç University Human Research Ethics Committee and accepted (decision number 2016.297. IRB3.144 on 08.02.2017). In addition the study was approved by the Spastic Children's Foundation of Turkey on 12.11.2016 and SERÇEV on 12.12.2016. After the parents who participated in the study were informed about the purpose of the study, their consent was obtained.

\section{Results}

While $88.1 \%$ of the parents participating in the study are mothers, $1.9 \%$ are fathers. $94.1 \%$ of the parents stated that they were married. When the mothers' ages are examined; It was found that $16.3 \%$ were $20-29$ and $83.7 \%$ were 30 and over. $23.1 \%$ of them are university graduates; It was observed that $86.6 \%$ of them did not work. $71.4 \%$ of the fathers are in the $40-49$ age group, $7.1 \%$ are primary school, $14.3 \%$ high school and $71.4 \%$ are university graduates. $57.1 \%$ of the fathers were working; $42.9 \%$ of them stated that they did not work. $61.0 \%$ of the parents evaluated their economic status as medium. While $85.6 \%$ of the parents stated that they do not have any other disabled children; $12.7 \%$ of them stated that they also have other physically or mentally disabled children. While $50 \%$ of the parents stated that they were someone with whom they regularly shared the care of their children with $\mathrm{CP}$, it is seen that the person who received the most help was spouse with $33.9 \%$. When the parents included in the study were asked if they had any education related to CP; While $39.8 \%$ of them stated that they received training, $50 \%$ stated education was sufficient, and the other $50 \%$ found it insufficient. $44.1 \%$ of the children are in the $7-12$ age group, $28 \%$ are in the $1-6$ age group and the same proportion is between the ages of $13-18.62 .7 \%$ of the children are boys and $78.8 \%$ attend school. It was observed that $44.8 \%$ went to special education schools, $18.4 \%$ to public schools and schools where inclusive education continues. When parents were asked whether their children had any other health problems with $\mathrm{CP}, 42.4 \%$ answered yes. 
Table 1. Children's Disease-Related Characteristics ( $\mathrm{N}=118)$

\begin{tabular}{lcc}
\hline Characteristics & Number & \% \\
\hline Time Since Diagnosis & 15 & \\
\hline 36 months and under & 25 & 12.7 \\
\hline $37-72$ months & 37 & 21.2 \\
\hline $73-108$ months & 29 & 31.3 \\
\hline 109 months and over & 12 & 24.6 \\
\hline Unanswered & & 10.2 \\
\hline Spasticity Degree & 29 & \\
\hline Mild & 52 & 24.6 \\
Moderate & 34 & 44.1 \\
\hline Severe & 3 & 28.8 \\
\hline Unanswered & & 2.5 \\
\hline Use of Drugs to Reduce Spasticity & 23 & 19.5 \\
\hline Yes & 88 & 74.6 \\
No & 7 & 5.9 \\
\hline Unanswered & & \\
\hline Number of Days/Weeks of Rehabilitation & 25 & 21.2 \\
\hline 1 Day & 52 & 44.1 \\
2 Days & 19 & 16.1 \\
3 Days & 22 & 18.6 \\
4-5 Days & 115 & \\
\hline Rehabilitation & 3 & 2.5 \\
\hline Yes & & \\
No & & \\
\hline
\end{tabular}

Table 1 shows the characteristics of children related to the disease. $12.7 \%$ of children have been diagnosed with CP for 36 months and less, $21.2 \%$ have been diagnosed with CP for 37-72 months, 31.3\% have been diagnosed with SP for 73-108 months, and 24.6\% have been diagnosed with CP for 109 months and longer. In children covered by the study, spasticity was mild in $24.6 \%$, moderate in $44.1 \%$ and severe in $28.8 \%$. $74.6 \%$ of children were found not to use drugs that reduce spasticity, and the proportion of those who took the drug was $19.5 \%$. In addition, $97.7 \%$ of children receive a regular rehabilitation service, $21.2 \%$ of children attend a rehabilitation center one day a week, $44.1 \%$ of children attend two days, $16.1 \%$ of children attend three days, and $18.6 \%$ of children attend a 
rehabilitation center four or five days.

Table 2. Average and standard deviation values of the family assessment device $(n=118)$

\begin{tabular}{lcc}
\hline Dimension & Min-Max & $\bar{X} \pm \mathbf{S S}$ \\
\hline Problem Solving & $1-4$ & $1.62 \pm 0.62$ \\
\hline Communation & $1-3$ & $1.75 \pm 0.59$ \\
\hline Roles & $1-3$ & $2.09 \pm 0.53$ \\
\hline Affective Responsiveness & $1-4$ & $1.72 \pm 0.67$ \\
\hline Affective Involvement & $1-4$ & $2.40 \pm 0.58$ \\
\hline Behavior Control & $1-3$ & $2.04 \pm 0.42$ \\
\hline General Functioning & $1-3$ & $1.62 \pm 0.54$ \\
\hline
\end{tabular}

According to the sub-dimensions of the parents" Family Assessment Device (FAD), the average score ranges from $1.62 \pm 0.54 / 0.62$ to $2.40 \pm 0.58$. When the cut point is taken as an average score of 2.00 , problem solving, communication, affective responsiveness and general functioning, below the mean score; the roles, behavior control, and affective involvement sub-dimension scores above the cut score. When the mean scores of the scale sub-dimensions of the parents are listed in ascending order; it followed as problem solving (1.62 \pm 0.62$)$, general functions (1.62 \pm 0.54$)$, affective responsiveness (1.72 \pm 0.67$)$, communication $(1.75 \pm 0.59)$, behavior control $(2.04 \pm 0.42)$, roles $(2.09 \pm 0.53)$, and showing the affective involment $(2.40 \pm 0.58)$.

In Table 3, the difference between parents was found to be statistically significant compared to the mother or father of the parent interviewed, with respect to roles, affective responsiveness and affective involment $(\mathrm{p}<0.05)$. Between roles and the affective involvement depending on the mother's educational status and the difference between the average score according to the mother's working status in the problem solving sub-dimension were statistically significant $(\mathrm{p}<0.05)$. The difference in the subscales of communication and affective responsiveness as well as depending on the income status of the parents as well as the difference between the average score on the subscales of emotional responsiveness and showing the affective involment were statistically significant $(\mathrm{p}<0.05)$. According to parents ' status of having other disabled children, sharing care, and receiving education related to $\mathrm{CP}$; the difference between the score averages, whether parents have someone to share their child's care properly, problem solving and general functions was significant $(\mathrm{p}<0.05)$. 
Table 3. FAD scores based on sociodemographic characteristics of parents

\begin{tabular}{|c|c|c|c|c|c|c|c|c|c|c|c|c|c|c|c|}
\hline \multirow[t]{2}{*}{$\begin{array}{l}\text { Sociodemographic } \\
\text { Characteristics }\end{array}$} & \multirow[t]{2}{*}{ Num } & \multicolumn{2}{|c|}{$\begin{array}{l}\text { Problem } \\
\text { s. }\end{array}$} & \multicolumn{2}{|c|}{ Commu. } & \multicolumn{2}{|c|}{ Roles } & \multicolumn{2}{|c|}{$\begin{array}{l}\text { Affective } \\
\text { Respons. }\end{array}$} & \multicolumn{2}{|c|}{$\begin{array}{l}\text { Affective } \\
\text { Involv. }\end{array}$} & \multicolumn{2}{|c|}{$\begin{array}{l}\text { Behavior } \\
\text { Control }\end{array}$} & \multicolumn{2}{|c|}{$\begin{array}{c}\text { General } \\
\text { Funct. }\end{array}$} \\
\hline & & $\bar{X}$ & ss & $\bar{X}$ & ss & $\bar{X}$ & ss & $\bar{X}$ & ss & $\bar{X}$ & ss & $\bar{X}$ & ss & $\bar{X}$ & Ss \\
\hline \multicolumn{16}{|l|}{ Parents } \\
\hline Mother & 104 & 1,63 & 0,63 & 1,78 & 0,61 & 2,13 & 0,53 & 1,78 & 0,68 & 2,44 & 0,58 & 2,05 & 0,42 & 1,65 & 0,54 \\
\hline Father & 14 & 1,59 & 0,57 & 1,50 & 0,36 & 1,74 & 0,38 & 1,26 & 0,44 & 2,12 & 0,50 & 2,02 & 0,43 & 1,41 & 0,47 \\
\hline U & & \multicolumn{2}{|c|}{600,50} & \multicolumn{2}{|c|}{408,00} & \multicolumn{2}{|c|}{286,50} & \multicolumn{2}{|c|}{266,00} & \multicolumn{2}{|c|}{378,00} & 445 & 5,00 & 395 & 5,50 \\
\hline $\mathrm{P}$ & & 0,96 & & 0,1 & 143 & 0,02 & 28 & 0,0 & & 0,0 & 039 & 0,5 & 50 & 0,1 & 21 \\
\hline Marital Status & & & & & & & & & & & & & & & \\
\hline Married & 111 & 1,60 & 0,60 & 1,74 & 0,58 & 2,10 & 0,53 & 1,72 & 0,66 & 2,40 & 0,58 & 2,05 & 0,42 & 1,63 & 0,55 \\
\hline Single & 7 & 2,03 & 0,87 & 1,76 & 0,74 & 1,97 & 0,45 & 1,81 & 0,91 & 2,43 & 0,52 & 1,89 & 0,31 & 1,47 & 0,33 \\
\hline $\mathrm{U}$ & & 213 , & & 269 , & 9,50 & 274 &, 50 & 329 & & 280 & 0,00 & 198 & 3,00 & 264 & 1,50 \\
\hline $\mathrm{P}$ & & 0,00 & & 0,95 & 958 & 0,51 & 16 & 0,8 & & 0,8 & 876 & 0,0 & 08 & 0,7 & 08 \\
\hline Mother's age & & & & & & & & & & & & & & & \\
\hline $20-29$ years old & 17 & 1,56 & 0,49 & 1,76 & 0,61 & 2,21 & 0,58 & 1,76 & 0,62 & 2,41 & 0,82 & 2,21 & 0,51 & 1,71 & 0,69 \\
\hline $30-39$ years old & 53 & 1,70 & 0,66 & 1,88 & 0,61 & 2,15 & 0,54 & 1,86 & 0,68 & 2,47 & 0,47 & 1,99 & 0,40 & 1,74 & 0,53 \\
\hline $40-49$ years old & 34 & 1,55 & 0,65 & 1,64 & 0,61 & 2,06 & 0,49 & 1,67 & 0,71 & 2,41 & 0,60 & 2,00 & 0,41 & 1,44 & $\mathbf{0 , 4 3}$ \\
\hline KW & & 1,3 & & 2,9 & 93 & 2,0 & & 0,3 & & 1, & 36 & 6 , & 09 & 7,7 & 71 \\
\hline $\mathrm{P}$ & & 0,51 & & 0,23 & 231 & 0,75 & 58 & 0,3 & & 0,5 & 507 & 0,0 & 39 & 0,0 & 21 \\
\hline Mother's Education & & & & & & & & & & & & & & & \\
\hline Primary school & 25 & 1,67 & 0,72 & 1,88 & 0,66 & 2,41 & 0,43 & 1,97 & 0,77 & 2,72 & 0,51 & 2,09 & 0,40 & 1,65 & 0,46 \\
\hline Secondary School & 16 & 1,64 & 0,65 & 1,78 & 0,57 & 2,17 & 0,46 & 1,80 & 0,56 & 2,43 & 0,59 & 2,02 & 0,30 & 1,76 & 0,63 \\
\hline High School & 33 & 1,59 & 0,56 & 1,86 & 0,58 & 2,08 & 0,59 & 1,82 & 0,65 & 2,30 & 0,53 & 2,04 & 0,47 & 1,69 & 0,58 \\
\hline University and above & 30 & 1,62 & 0,64 & 1,62 & 0,64 & 1,95 & $\mathbf{0 , 5 0}$ & 1,60 & 0,67 & 2,36 & 0,62 & 2,04 & 0,45 & 1,55 & 0,52 \\
\hline $\mathrm{KW}$ & & 0,0 & & 2,8 & 85 & 11,2 & 25 & 4,9 & & 9 & 31 & 0 & 46 & 1,4 & 47 \\
\hline $\mathrm{P}$ & & 0,99 & & 0,41 & 415 & 0,01 & 10 & 0,1 & & 0,0 & 025 & 0,9 & & 0,6 & 889 \\
\hline & & $\bar{X}$ & ss & $\bar{X}$ & ss & $\bar{X}$ & ss & $\bar{X}$ & ss & $\bar{X}$ & ss & $\bar{X}$ & ss & $\bar{X}$ & Ss \\
\hline Working Status Of 1 & & & & & & & & & & & & & & & \\
\hline Working & 13 & 2,13 & 0,78 & 1,91 & 10,56 & 2,29 & 0,40 & 1,75 & 0,59 & 2,56 & 0,52 & 2,13 & 0,31 & 1,74 & 0,50 \\
\hline Not Working & 90 & 1,55 & 0,57 & 1,76 & $\begin{array}{ll}6 & 0,62\end{array}$ & 2,10 & 0,54 & 1,79 & 0,69 & 2,42 & 0,59 & 2,03 & 0,44 & 1,64 & 0,55 \\
\hline 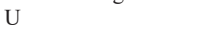 & & & 4,00 & & 69,00 & & 4,50 & 477 & 7,00 & & 4,50 & 34 & 3,00 & 343 & 3,00 \\
\hline $\mathrm{P}$ & & & 014 & &, 419 & & 147 & 0,9 & 972 & & 447 & & 279 & 0,4 & 155 \\
\hline Father's age & & & & & & & & & & & & & & & \\
\hline $30-39$ ages & 4 & 2,00 & 0,47 & 1,72 & 20,33 & 1,82 & 0,43 & 1,17 & 0,17 & 2,46 & 0,65 & 2,03 & 0,66 & 1,61 & 0,77 \\
\hline 40-49 ages & 10 & 1,41 & 0,53 & 1,40 & $\begin{array}{ll}0 & 0,34\end{array}$ & 1,70 & 0,38 & 1,30 & 0,51 & 1,97 & 0,36 & 2,01 & 0,33 & 1,34 & 0,36 \\
\hline $\mathrm{U}$ & & &, 00 & & 9,00 & & 1,00 & 12 & 50 & & 0,00 & &, 50 & 11 , & 00 \\
\hline $\mathrm{P}$ & & & 044 & & 156 & & 569 & 0,8 & 843 & & 213 & & 544 & 0,6 & \\
\hline Working Status O & & & & & & & & & & & & & & & \\
\hline Wo & 8 & 1,83 & 0,60 & 1,73 & 30,28 & 1,84 & 0,40 & 1,47 & 0,55 & 2,29 & 0,54 & 2,06 & 0,55 & 1,58 & 0,60 \\
\hline Not Working & 6 & 1,31 & 0,41 & 1,22 & 20,23 & 1,57 & 0,32 & 1,06 & 0,14 & 1,93 & 0,41 & 1,96 & 0,23 & 1,24 & 0,22 \\
\hline $\mathrm{U}$ & & & 0,50 & & 4,50 & & 00 & 6, & 00 & & 4,00 & 16 & 00 & 12 , &, 50 \\
\hline $\mathrm{P}$ & & & 127 & &, 016 & & 255 & 0,0 & 039 & & 313 & & 304 & 0,3 & 371 \\
\hline Incon & & & & & & & & & & & & & & & \\
\hline Enou & 21 & 1,59 & 0,69 & 1,65 & $5 \quad 0,60$ & 1,95 & 0,45 & 1,42 & $\mathbf{0 , 5 3}$ & 2,13 & 0,45 & 1,97 & 0,42 & 1,45 & 0,43 \\
\hline Modarete & 72 & 1,63 & 0,58 & 1,81 & $1 \quad 0,59$ & 2,15 & 0,57 & 1,83 & 0,66 & 2,46 & 0,61 & 2,04 & 0,44 & 1,68 & 0,56 \\
\hline Not Enough & 25 & 1,64 & $+0,69$ & 1,67 & $\begin{array}{l}7 \quad 0,59 \\
-19\end{array}$ & 2,06 & 0,46 & 1,70 & 0,76 & 2,46 & 0,53 & 2,11 & 0,36 & 1,61 & 0,55 \\
\hline KW & & &, 39 & & 1,58 & & 31 & 7 & 50 & & ,66 & 1 , & 06 & 2 , & 19 \\
\hline $\mathrm{P}$ & & & 823 & &, 454 & & 316 & 0,0 & 024 & & 042 & & 588 & 0,3 & 335 \\
\hline Number of children & & & & & & & & & & & & & & & \\
\hline 1 child & 34 & 1,65 & 0,58 & 1,73 & 30,58 & 2,01 & 0,51 & 1,82 & 0,69 & 2,45 & 0,59 & 2,11 & 0,40 & 1,61 & 0,48 \\
\hline 2 children & 55 & 1,61 & 0,64 & 1,73 & 30,60 & 2,06 & 0,55 & 1,61 & 0,64 & 2,38 & 0,57 & 1,95 & 0,34 & 1,55 & 0,55 \\
\hline 3 children and above & 29 & 1,62 & 0,64 & 1,79 & 90,61 & 2,25 & 0,49 & 1,87 & 0,71 & 2,39 & 0,60 & 2,18 & 0,55 & 1,77 & 0,56 \\
\hline KW & & &, 05 & & 0,09 & & 39 & 5 , & 63 & &, 15 & 6 , & 78 & 1, & 28 \\
\hline $\mathrm{P}$ & & & 952 & &, 912 & & 044 & 0,0 & 041 & & 863 & & 037 & 0,2 & \\
\hline
\end{tabular}

According to whether the child had any other health problems other than $\mathrm{CP}$, the mean values of FAD sub-dimensions of the parents for all dimensions other than behavior control and depending on the child's school attendance status, the difference between the average score of parents who attend and do not attend school were significant in the roles, emotional response, behavior control and general functions $(\mathrm{p}<0.05)$. 
Table 4. Parents' FAD scores based on children's disease-related characteristics.

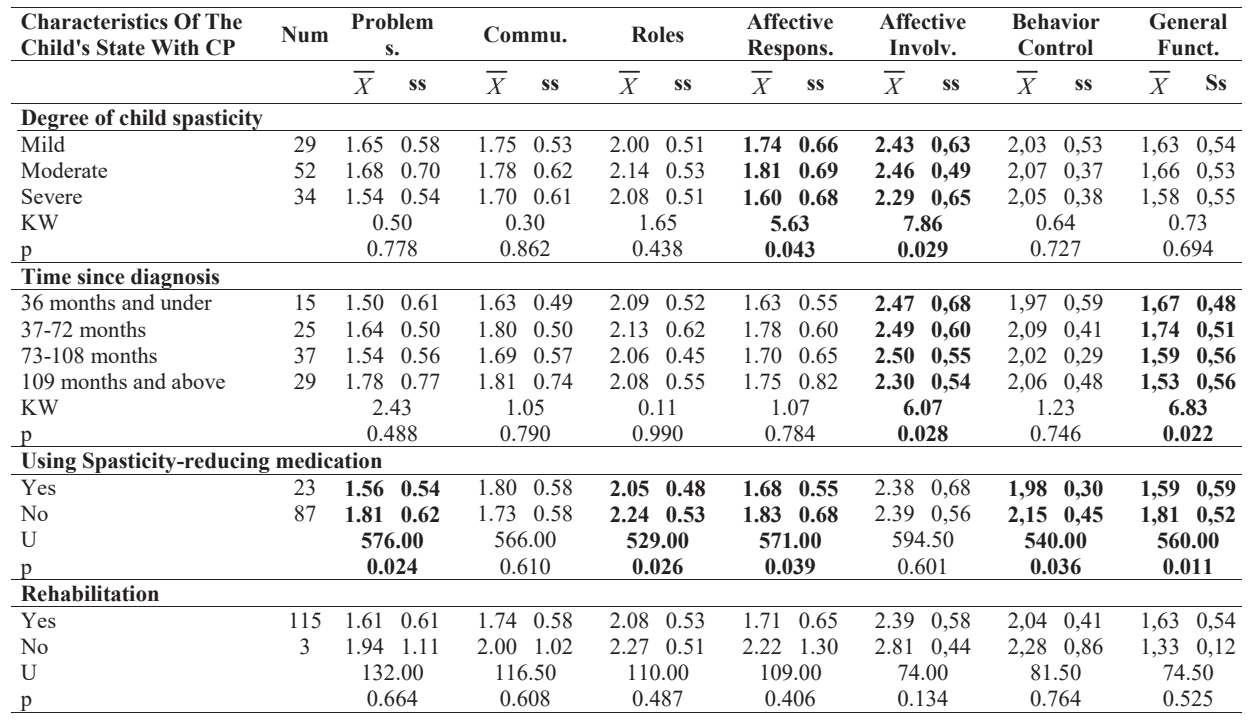

In Table 4, when the subscale averages of the parents involved in the study were taken into account, the average score of the parents of children with moderate spasticity in all subscales of the FAD was higher than the parents of children with mild or severe spasticity. The difference in the subscales of affective responsiveness and showing the affective involment and the time elapsed since the diagnosis of the child and the mean of the affective involment and general functions of the subscale score as well as problem solving, roles, affective responsiveness, behavior control and general functions between both groups, depending on whether a child with $\mathrm{CP}$ is taking a drug that reduces spasticity were statistically significant $(\mathrm{p}<0.05)$.

\section{Discussion}

Having a new baby in the family requires reorganization of roles and also new routines need to be established in the family but if the child is disabled, expectations and plans change. Therefore, it impacts the dynamics of the family dimensions. Families are trying to get used to this role change. Having a child with CP can lead to a deterioration of the family functions in family life $(16,20)$. In the organization of nursing care for families with children with disabilities, it is important to evaluate the functions of family structures. According to the our results, mothers participated in the study more than fathers. Most of the parents were over the age of 30 as well as majority were graduated from college and more than half of the mothers are unemployed. In consonance with sociodemographic 
characteristics of the studies of Fiss et al. (2013) most of the relationships of the children were with their mothers. The education level for majority of the families is high school and above and most of them are unemployed. The sociodemographic characteristics of this study are in parallel with the results of our study (20).

The fact that most of the mothers are unemployed can be explained by the high need for continuous care of the child with $\mathrm{CP}$ and the fact that the mothers mainly assume the care responsibility. The main responsibilty of mothers in society is characterized by childcare. The majority of the care burden of the child is on the mothers. The reason for their unemployment may be that mothers quit their jobs to take care of their children. In the study conducted by Turan et al, most of the mothers who care for disabled children are housewives. They found that families with income equal to and less than expenses are more (21). According to the another research which the relationship between $\mathrm{CP}$ and socioeconomic status was systematically examined, families with low socioeconomic status were reported to increase the risk of CP in 8 out of 20 studies (22).

While half of the parents stated that they are someone with whom they share the care of their children regularly, it is seen that the biggest helper is their spouse in our research. In a study by Cigerli et al. (2014) some parents expect more attention-sharing from their spouses and some want support from the social environment and preferred to form groups with other disabled families (23).

Half of the families participating in our research stated that the education related to $\mathrm{CP}$ is insufficient. Providing education is one of the nursing roles. Familycentered nursing care is very important in order to receive sufficient education about the current situation of the children, to eliminate uncertainties and also to improve the quality of care. In addition to all these, family members of children with neurodevelopmental disabilities such as $\mathrm{CP}$, who received more familycentered approach, reported less depression and distress (24).

Most of the children participating in our research are male. In the study conducted by Köseoğlu et al. (2014) which examined the demographic characteristics of children with CP, 51 of the 132 cases were found to be girls $38.6 \%$ and boys $61.4 \%$ (24). Our results on gender are similar to this study (25).

In our study, the mean scores of the sub-dimensions of problem solving, communication, roles, affective involvement and general functions were found to be higher in the parents who stated that they had other disabled children. There is an important relationship between affective involvement score and other disabled child in the family as stated in our research. Having more than one disabled child in the family causes an increase in the number of family members to be cared for. In this case, it is inevitable that time allocated to care and treatment will be 
a priority in the family. The burden of care causes family members not to show enough love, care and affection for each other. Şimşek et al. (2015) found that families with a disabled child postponed their desire to have a child thinking that their next child may also be disabled. When families learn that they have another disabled child, their shock is undeniable. (26).

The mean scores of all sub-dimensions of parents who stated that they did not share their child's care with another person were found to be higher than the mean scores of parents who stated that they shared care. In terms of the problem solving general functions score in our research, the care and treatment of the child with $\mathrm{CP}$ increases the responsibilities and burden of the parents. It is observed that families who do not share the care of the child equally cannot provide enough coping power in the period from the emergence of problems to the solution process. This can be explained by the fact that all care-related responsibilities are placed on one person and therefore these person cannot provide and show problem solving skills $(15,19)$.

\section{Conclusion and Recommendations}

Nurses and health professionals should consider the child and family as a whole while providing care. They should evaluate the family functions with all subdimensions, considering that the problem in the family may also affect the care of the child. Low family functions should be improved by family-centered nursing care, and the quality of family functions should be ensured.

\section{References}

1. Graham K, Rosenbaum P, Paneth N, Dan B, Lin JP, Damiano D, et al. Cerebral palsy. Nature Reviews Disease Primers. 2016;2. 15082. 10.1038/nrdp.2015.82.

2. Yalçınkaya YE, Karaağaç F, Ayna AB, Önş K. Body Weight Percent in Children with Cerebral Palsy. Okmeydanı Medical Journal. 2015;31(3): 144-147.

3. National Institute of Neurological Disorders and Stroke (NINDS). NINDS Cerebral Palsy Information Page.2016.

4. Marret S, Vanhulle C, Laquerrière A. Pathophysiology of cerebral palsy. Handbook of clinical neurology. 2013;111. 169-76. 10.1016/B978-0444-52891-9.00016-6.

5. Novak I, Morgan C, Adde L, Blackman J, Boyd, RN, BrunstromHernandez J, CioniG, et al. Accurate Diagnosis and Early Intervention in Cerebral Palsy: Advances in Diagnosis and Treatment. JAMA pediatrics. 2017;171(9), 897-907. https://doi.org/10.1001/ 
jamapediatrics.2017.1689

6. McIntyre S, Taitz D, Keogh J, Goldsmith S, Badawi N, Blair E.A Systematic Review Of Risk Factors For Cerebral Palsy İn Children Born At Term İn Developed Countries. Dev Med Child Neurol. 2013;55 (6): 499-508.

7. T.C. Prime Ministry General Directorate of Family and Social Research. Family Values Survey climate of Turkey. (Edition 1) Ankara: Manas San. Tic. Ltd.Şti Advertising Services Media Planning.2010:14-204.

8. Sivrikaya T, Tekinarslan İÇ. Stress, Social Support and Family Burden in Mothers with Mentally Disabled Children. Ankara University Faculty of Educational Sciences Special Education Journal. 2013;14 (2): 17-29.

9. Yildırım A, Vaccines, HR, Karakurt P. Determination of Mental Status of Mothers of Disabled Children. İ.Ü.F.N. Both. Journal. 2012;20 (3): 200-209.

10. Lara EB, Pinos C. Families with a Disabled Member: Impact and Family Education. Procedia - Social and Behavioral Sciences. 2017;237. 418425. 10.1016/j.sbspro.2017.02.084.

11. Wiegand-Grefe S, Sell M, Filter B, Plass-Christl A.Family Functioning and Psychological Health of Children with Mentally Ill Parents. International journal of environmental research and public health. 2019;16(7), 1278. https://doi.org/10.3390/ijerph16071278

12. Girgin BA, Balc1 S.Home Care Needs of Physically Handicapped Child and Family. Gümüşhane University Journal of Health Sciences. 2015;4 (2); 305-317.

13. Spratt T.Families with multiple problems: Some challenges in identifying and providing services to those experiencing adversities across the life course. Journal of Social Work. 2011;11.343-357. $10.1177 / 1468017310379256$.

14. Iacolinoa, C.Pellerone M.Pace U,Ramaci T,Castorina V. Family functioning and disability: a study on Italian parents with disabled children. 2016;39-52. 10.15405/epsbs.2016.05.5.

15. Bernardi F, J Härkönen D, Boertien, AR, Bastaits K. Mortelmans D.Effects of family forms and dynamics on children's well-being and life chances: literature review. Families and Societies Working Paper Series. 2013;3:2-32.

16. Duran S. Families of Mentally Disabled Children and Psychiatric Nursing. 
Turkiye Klinikleri J Psychiatr Nurs-Special Topics. 2018;4(1):74-80.

17. Cakmak FH, Gul H.Factors associated with problematic internet use among children and adolescents with Attention Deficit Hyperactivity Disorder. Northern clinics of Istanbul. 2018;5(4), 302-313. https://doi. org/10.14744/nci.2017.92668

18. Yigit $\mathrm{T}$,Parlar H.The Relationship Between Family Assessment and Problem Solving Assessment Levels: Relationship Between Family Assessment and Problem Solving Assessment Levels.2018; 1.36-44.

19. Shevell M, Oskoui M, Wood E, Kirton A, Van Rensburg E, Buckley D, NG P, Majnemer A.Family-centred health care for children with cerebral palsy. Developmental medicine and child neurology. 2019;61(1), 62-68. https://doi.org/10.1111/dmcn.14053

20. LaForme Fiss, Chiarello LA, Bartlett D, Palisano RJ, Jeffries L, Almasri N, Chang HJ. Family ecology of young children with cerebral palsy. Child: care, health and development.2014;40(4), 562-571. https:// doi.org/10.1111/cch.12062

21. Turan F,Dalgıç Aİ. Family Burden Among Parents Of Children With Intellectual Disability. Journal of Psychiatric Nursing. Journal of Psychiatric Nursing. 2017;8(1):9-16.

22. Solaski M, Majnemer A, Oskoui M Contribution of socio-economic status on the prevalence of cerebral palsy: a systematic search and review. Dev Med Child Neurol. 2014 Nov; 56 (11): 1043-51.

23. Ciğerli Ö, Topsever P, Alvur TM, Görpelioğlu S.Parenting Experiences of Parents with Disabled Children From the Time of Diagnosis: Accepting the Difference. Turkish Journal of Family Medicine and Primary Care. 2014; 8 (3): 86-92.

24. Aydın R, Nur H.Family-Focused Approach in the Treatment of Children with Cerebral Palsy, Turkish Phys Medicine Rehab Derg. 2012; 58: 22935 .

25. Köseoğlu E, Karaoğlan B, Zinnuroğlu M.Demographic Data and Clinical Features of 132 Cases with Cerebral Palsy, FTR Bil Der. 2014; 17: 161165.

26. Şimşek TT, Taşçı M, Karabukut D.The Willingness to Have Another Child in Families With Chronically Handicapped Children and Its Effect on Parent Unity, Turk Pediatri Ars.2015; 50: 163-9. 